Article

\title{
Pinecone-Derived Activated Carbons as an Effective Medium for Hydrogen Storage
}

\author{
Sara Stelitano ${ }^{1,2}{ }^{\circ}$, Giuseppe Conte ${ }^{1}$, Alfonso Policicchio ${ }^{1,3,4, *} \mathbb{C}$, Alfredo Aloise ${ }^{5}$, \\ Giovanni Desiderio 4,6 ${ }^{(D)}$ and Raffaele G. Agostino 1,3,4,6 \\ 1 Dipartimento di Fisica, Università della Calabria, Via Pietro Bucci cubo 31C, 87036 Arcavacata di Rende (CS), \\ Italy; sara.stelitano@rina.org (S.S.); giuseppe.conte@unical.it (G.C.); raffaele.agostino@fis.unical.it (R.G.A.) \\ 2 RINA Consulting - CSM S.p.A., Zona Industriale San Pietro Lametino SNC, 88046 Lamezia Terme (CZ), Italy \\ 3 CNISM - Consorzio Nazionale Interuniversitario per le Scienze fisiche della Materia, Via della Vasca Navale \\ 84, 00146 Rome (RM), Italy \\ 4 Consiglio Nazionale delle Ricerche, Istituto di Nanotecnologia (Nanotec) - UoS Cosenza, Via Ponte P. Bucci, \\ Cubo 31C, 87036 Arcavacata di Rende (CS), Italy; giovanni.desiderio@cnr.it \\ 5 Dipartimento Ingegneria per l'Ambiente e il Territorio e Ingegneria Chimica, Università della Calabria, \\ Via Ponte P. Bucci, Cubo 42A, 87036 Arcavacata di Rende (CS), Italy; alfredo.aloise@unical.it \\ 6 DeltaE s.r.l., c/o Università della Calabria, Via Pietro Bucci cubo 31D, 87036 Arcavacata di Rende (CS), Italy \\ * Correspondence: alfonso.policicchio@fis.unical.it; Tel.: +39-0984-49-6095; Fax: +39-0984-49-4401
}

Received: 12 March 2020; Accepted: 24 April 2020; Published: 3 May 2020

check for updates

\begin{abstract}
Pinecones, a common biomass waste, has an interesting composition in terms of cellulose and lignine content that makes them excellent precursors in various activated carbon production processes. The synthesized, nanostructured, activated carbon materials show textural properties, a high specific surface area, and a large volume of micropores, which are all features that make them suitable for various applications ranging from the purification of water to energy storage. Amongst them, a very interesting application is hydrogen storage. For this purpose, activated carbon from pinecones were prepared using chemical activation with different $\mathrm{KOH} /$ precursor ratios, and their hydrogen adsorption capacity was evaluated at liquid nitrogen temperatures $(77 \mathrm{~K})$ at pressures of up to 80 bar using a Sievert's type volumetric apparatus. Regarding the comprehensive characterization of the samples' textural properties, the measurement of the surface area was carried out using the Brunauer-Emmett-Teller method, the chemical composition was investigated using wavelength-dispersive spectrometry, and the topography and long-range order was estimated using scanning electron microscopy and X-ray diffraction, respectively. The hydrogen adsorption properties of the activated carbon samples were measured and then fitted using the Langmuir/ Töth isotherm model to estimate the adsorption capacity at higher pressures. The results showed that chemical activation induced the formation of an optimal pore size distribution for hydrogen adsorption centered at about $0.5 \mathrm{~nm}$ and the proportion of micropore volume was higher than $50 \%$, which resulted in an adsorption capacity of $5.5 \mathrm{wt} \%$ at $77 \mathrm{~K}$ and $80 \mathrm{bar}$; this was an increase of as much as $150 \%$ relative to the one predicted by the Chahine rule.
\end{abstract}

Keywords: Pinecones; biomass waste; nanoporous activated carbon; hydrogen storage; renewable

\section{Introduction}

The European Commission's Directive 2009/28/EC (renewable energy sources (RES) directive) has established that at least $20 \%$ of energy consumption must come from RES by 2020, and EU countries have agreed to a target of $27 \%$ by 2030 [1].

Thus RES, such as solar or wind, will play a significant role in electric power generation. The most prominent disadvantage of RES is their variability, which needs to be balanced for electric grid stability 
purposes. Consequently, long-term and large-capacity electricity storage is required, as well as reserve production capacity. Current storage systems present low energy densities or limited storage potential. There are different paths for the conversion of energy produced from RES into gaseous or liquid fuels. The power to gas $(\mathrm{PtG})$ processes represent one of the aforementioned alternatives. A PtG process connects the electrical network to the gas network by converting excess energy into gas through the conversion and storage of hydrogen $\left(\mathrm{H}_{2}\right)$ [2]. The challenge for PtG systems is the momentary $\mathrm{H}_{2}$ storage. Compressed and liquid forms are not considered economically viable options for $\mathrm{H}_{2}$ storage, while storage using solid-state materials could represent an interesting third solution [3,4].

Among different solid materials, carbon-based materials have attracted interest for their unique features (excellent stability, adjustable porosity, good electronic conductivity, etc.) that allow them to assume key functions in various technologies [5], such as gas and energy storage [4,6-12], water treatment [13], and/or carbon dioxide $\left(\mathrm{CO}_{2}\right)$ capture [14].

However, these carbon materials are generally products of fossil-fuel-based precursors (e.g., methane $\left(\mathrm{CH}_{4}\right)$, phenol, and pitch) that are created using methods that are dangerous and expensive for the natural environment. Biomass-derived carbon-based materials represent an efficient, greener, and low-cost alternative [15-18]. These display physicochemical characteristics [19], such as being suitable for obtaining carbon-based materials with desired properties for different applications [20-22].

Consequently, natural, organic, and agricultural wastes, such as corncob [23], wood [24], rice husks [25], olive stones [26], sucrose [27], and jute [28], have been explored as biomass sources for the production of activated carbons (ACs) [29] with high specific surface areas (SSAs) that are connected to a very determined porosity, both of which are basic parameters for $\mathrm{H}_{2}$ storage [30].

Generally, ACs are the result of a gradual process in which a pulverization phase is followed by the carbonization of the material in an inert gas atmosphere with an appropriate temperature trend. Subsequently, chemical or physical activation is performed [31]. The chemical activation process consists of the mixing of the carbon source with a chemically active agent. Among several chemically active agents [32], potassium hydroxide $(\mathrm{KOH})$ has been extensively utilized to activate the carbon as it allows for obtaining porous carbon with a well-defined micropore size distribution and a high SSA $\left(\leq 3000 \mathrm{~m}^{2} \mathrm{~g}^{-1}\right)$, which give rise to excellent storage properties [12,33-35].

It is commonly thought that ACs' porous structure is the crucial characteristic for $\mathrm{H}_{2}$ adsorption capacity. More specifically, a high SSA and a large volume of micropores, with diameters in the range of 6-8 $\AA$, are necessary for an efficient performance as an $\mathrm{H}_{2}$ storage material. In this field, the strategy is now dedicated to going beyond the so-called Chahine rule: the maximum adsorption capacity scales with the specific surface area at a rate of $1 \mathrm{wt} \%$ per $500 \mathrm{~m}^{2} / \mathrm{g}$, i.e., $6 \mathrm{H}_{2}$ molecules $/ \mathrm{nm}^{2}$ of the pore surface [36-38].

Pinecones, a widely available biomass, are mostly composed of cellulose and lignin [39,40], which means that it represents an interesting carbon source. Once pulverized, it has a porous structure that represents an excellent platform that can interact with and capture several chemical species, leading to an optimization of the structure in the final products. To date, as a porous carbon source, pinecones have been largely investigated as electrodes for supercapacitors and lithium-ion batteries [41] and for water treatment [42]; however, no reports on their use as an adsorbent for hydrogen storage has been reported. Toward this aim, new motivation was recently provided by the report of Blankenship et al. [43] on cellulose-acetate-derived microporous carbons with high SSAs and pore volumes, according to which, a high oxygen content noticeably improves the $\mathrm{H}_{2}$ adsorption capacity.

Based on the above, the objective of this work was to demonstrate that the modification of the morphology and textural properties of biomass-based porous carbons from pinecones synthesized using a chemical activation procedure represents a useful and convenient method for obtaining high-performance hydrogen storage materials. In particular, the focus of the study was on the effects of different $\mathrm{KOH} /$ pinecone powder weight ratios used during the synthesis procedure on the sample's porosity. Furthermore, detailed microstructure analysis using density function theory (DFT) and 
an evaluation of the hydrogen storage performance using a Sievert's type apparatus, as well as their correlation, was investigated and is reported herein.

\section{Experimental}

\subsection{Material and Sample Preparation}

Pinecones from stone pine (Pinus pinea) (Figure 1), collected from the local area of Sila, Italy, were used as raw materials. Distilled water was used to repeatedly wash all the cones to remove soluble impurities; they were then dried for $12 \mathrm{~h}$ at $353 \mathrm{~K}$. After drying, the cleaned cones were milled using a blender. The obtained pinecone powder (PC) was heated at $453 \mathrm{~K}$ for $5 \mathrm{~h}$ to remove the unwanted moisture [42] and the resultant powder was denoted as dehydrated pinecone powder (DPC). Then, the DPC was dissolved in $100 \mathrm{~mL}$ of demineralized water with $\mathrm{KOH} / \mathrm{DPC}$ ratios equal to $0.5,1$, and 3 . After stirring for $24 \mathrm{~h}$ at $353 \mathrm{~K}$, the black-colored mixture was dried at $373 \mathrm{~K}$ until the moisture was removed; then, using a ceramic crucible, it was transferred to a tubular furnace under a $100 \mathrm{~mL} / \mathrm{min}$ helium flow (99.999\% purity Helium). The sample was slowly heated to $1173 \mathrm{~K}$ at a heating rate of $5 \mathrm{~K} / \mathrm{min}$ and remained at this temperature for 2 hours. The steps of the transformation process of PC into porous carbons are schematically reported below in Figure 1.

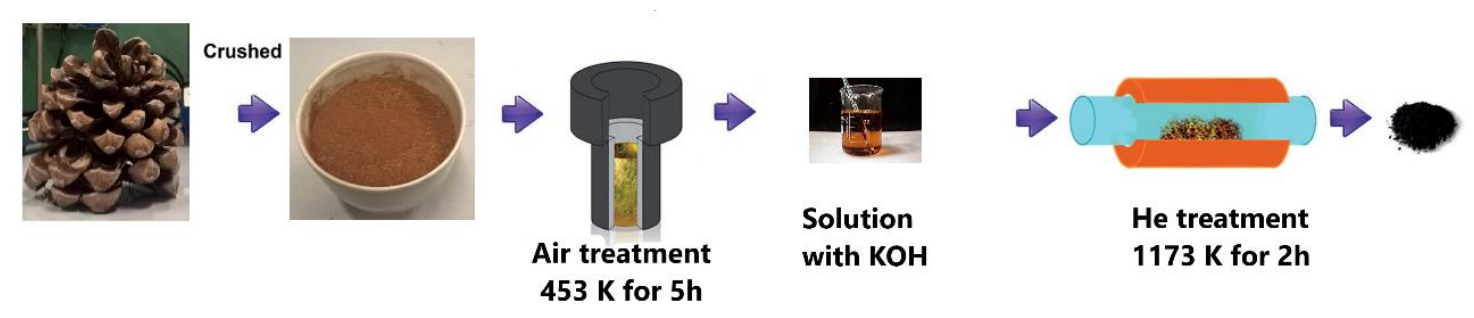

Figure 1. Schematic procedure for the preparation of the activated porous carbons from pinecones.

In the final step, distilled water was once again used to wash the resulting dark solid material until a $\mathrm{pH}=7$ condition was reached; then, the material was kept at $353 \mathrm{~K}$ for drying in an electric oven in air. The resultant powder was labeled ADPCx (activated carbonized pinecone), where " $x$ " denotes the $\mathrm{KOH} / \mathrm{DPC}$ ratio, as shown in Table 1. 
Table 1. Textural properties and $\mathrm{H}_{2}$ adsorption properties of the samples.

\begin{tabular}{|c|c|c|c|c|c|c|c|c|c|c|c|}
\hline \multirow{2}{*}{ Sample } & \multirow{2}{*}{$\begin{array}{l}\mathrm{KOH} / \\
\mathrm{DPC}\end{array}$} & \multirow{2}{*}{$\begin{array}{l}{ }^{a} S_{B E T} \\
\left(m^{2} / g\right)\end{array}$} & \multirow{2}{*}{$\begin{array}{c}{ }^{b} V_{T} \\
\left(\mathrm{~cm}^{3} / g\right)\end{array}$} & \multirow{2}{*}{$\begin{array}{l}{ }^{c} V_{\text {micro }} \\
\left(\mathrm{cm}^{3} / \mathrm{g}\right)\end{array}$} & \multicolumn{2}{|c|}{ DFT Cumulative Pore Volume $\left(\mathrm{cm}^{3} / \mathrm{g}\right)$} & \multirow{2}{*}{$\begin{array}{l}{ }^{f} V_{\text {meso }} \\
\left(\mathrm{cm}^{3} / \mathrm{g}\right)\end{array}$} & \multirow{2}{*}{$\begin{array}{c}\mathrm{g} \mathrm{V}_{\text {macro }} \\
\left(\mathrm{cm}^{3} / \mathrm{g}\right)\end{array}$} & \multirow{2}{*}{$\begin{array}{c}\mathrm{h}_{\text {micro }} \\
(\%)\end{array}$} & \multirow{2}{*}{$\begin{array}{c}{ }_{(\mathbf{i}}^{\mathrm{i}} \mathrm{H}_{2} \\
(\mathbf{w t} \%)\end{array}$} & \multirow{2}{*}{$\begin{array}{c}{ }^{1} \mathrm{H}_{2} \\
\left(w t^{\circ}\right)\end{array}$} \\
\hline & & & & & d Ultra-Micropores & e Super-Micropores & & & & & \\
\hline DPC & 0 & 0.42 & 0.003 & 0.0001 & 0 & 0.0001 & 0.0001 & 0.0028 & 3 & 0.00 & 0.00 \\
\hline ADPC0.5 & 0.5 & 441 & 0.1633 & 0.1506 & 0.0993 & 0.0513 & 0.0087 & 0.0041 & 92 & 0.73 & 1.79 \\
\hline ADPC1 & 1 & 1173 & 0.4513 & 0.3836 & 0.1854 & 0.1982 & 0.0630 & 0.0048 & 85 & 1.57 & 5.25 \\
\hline ADPC3 & 3 & 1050 & 0.4487 & 0.3254 & 0.1479 & 0.1775 & 0.1204 & 0.0030 & 73 & 1.28 & 3.40 \\
\hline
\end{tabular}

${ }^{a}$ SBET: Specific surface area (SSA) as a result of the Brunauer-Emmett-Teller (BET) method applied in the 0.05-0.15 relative pressure range. ${ }^{b} V_{T}$ : Estimated total pore volume with a relative pressure of $\mathrm{P} / \mathrm{P}_{0}=0.99 .{ }^{\mathrm{c}} \mathrm{V}_{\text {micro }}$ : Micropore volume extracted from the cumulative volume. ${ }^{\mathrm{d}}$ Ultramipores: Volume of pores with less than a $7 \AA$ width. e Supermicropores:

Volume of pores with less than a $20 \AA$ width. ${ }^{\mathrm{f}} \mathrm{V}_{\text {meso: }}$ : Pore volume with a diameter lower than $500 \AA$ in width. ${ }^{g} \mathrm{~V}_{\text {macro: }}$ : Macropore volume as the rest of the total pore volume once the micropore and mesopore volumes were subtracted. ${ }^{\mathrm{h}} \mathrm{F}_{\text {micro }}$ : Micropore volume fraction $=\left(\right.$ micropore volume/total pore volume) $\times 100 .{ }^{i} \mathrm{H}_{2}$ uptake: Hydrogen storage capacity at $77 \mathrm{~K}$ and 1 bar. ${ }^{1} \mathrm{H}_{2}$ uptake: Hydrogen storage capacity at $77 \mathrm{~K}$ and 80 bar. DPC: Dehydrated pinecone powder, ADPC: Activated carbonized pinecone, DFT: Density function theory. 


\subsection{Characterization}

Morphological scanning electron microscope (SEM) images were recorded using an FEI Quanta 200 FEG, a field emission SEM, using an electron beam of $20 \mathrm{keV}$ to track any change in the morphology of the samples after the activation process. A chemical composition estimation was obtained using a JEOL JXA-8230 electron probe micro-analyzer (EPMA) equipped with five wavelength-dispersive spectrometers (WDS).

The phase structure of the samples was examined using X-ray powder diffraction (XRD) patterns acquired in reflection mode on a Philips PW 1830 diffractometer equipped with $\mathrm{Cu} K \alpha(40 \mathrm{kV}, 40 \mathrm{~mA})$ filtered radiation. All patterns were recorded in the $2 \theta$ range from $2^{\circ}$ to $70^{\circ}$, with steps of $0.02^{\circ}$ and a counting time of $1 \mathrm{~s}$ per step, at room temperature ( $\mathrm{RT} \approx 298 \mathrm{~K}$ ); the sample stage effect was taken into consideration.

A Micromeritics ASAP 2460 apparatus was used to measure the $\mathrm{N}_{2}$ adsorption isotherms at $77 \mathrm{~K}$ to evaluate the sample's textural properties. All samples were subjected to a thermal treatment at $473 \mathrm{~K}$ for $12 \mathrm{~h}$ in a vacuum before each adsorption test. The Brunauer-Emmett-Teller (BET) method [44] was applied in the $0.05-0.15$ relative pressure range to extrapolate the specific surface area of each sample, while $\mathrm{V}_{\mathrm{T}}$, the total pore volume, was assessed by recording the $\mathrm{N}_{2}$ uptake at a relative pressure $\mathrm{P} / \mathrm{P}_{0}$ of 0.995. Density functional theory (DFT), considering slit-shaped pores [45], was used to calculate the total micropore volume $\left(\mathrm{V}_{\text {micro }}\right)$ and the pore size distributions (PSDs) to estimate the trends in the porosity changes. The $\mathrm{H}_{2}$ adsorption capacity at $77 \mathrm{~K}$ was evaluated for different pressure ranges, in particular from 0 to 1 bar and from 0 to 80 bar, using the Micromeritics ASAP 2460 instrument and a Sieverts' type apparatus (fPcT) [46], respectively. Before each adsorption/desorption measurements, all investigated materials were treated at high temperature $(\approx 473 \mathrm{~K})$ overnight. The gas storage uptake ( $w t \%$-weight percent of adsorbed gas per gram of adsorbent) was established through an analysis of the adsorption isotherms.

\section{Results and Discussion}

\subsection{Surface and Structure Analysis}

SEM images of the DPC and ADPC samples are shown below in Figure 2. Figure 2a clearly shows the smooth surface of the carbonized sample containing few micropores, while a sponge-like morphology with a heterogeneous distribution of pores was present for the activated ones (Figure $2 b-d$ ). The pores were larger for higher $\mathrm{KOH} / \mathrm{DPC}$ ratios, leading to the presence of a microporous structure on the walls separating the macropores, which is shown in the insets. Here, we confirm that the formation of porous cavities in the material was produced by the $\mathrm{KOH}$ activation process [33-35].

In Figure 3, the XRD patterns in the $15-35^{\circ} 2 \theta$ range of all samples are reported. The DPC sample showed a broad peak centered at $2 \theta=23^{\circ}(002)$, denoting the typical amorphous graphite structure $[24,31,47]$. The $(002)$ peak disappeared in the activated samples, confirming the amorphous and non-graphitic nature of the ADPCs samples. The pore network was an outcome of the activation process, i.e., a series of redox reactions between the carbon material and the potassium compounds, as well as at the temperature evolution timing during the next carbonization process, led to the selective dissolution of the species on the carbon framework surface, $[24,25,27,34]$.

WDS analysis (Supplementary Table S1) showed that the samples mainly consisted of carbon and oxygen, with 81.3 at $\%$ and 17.7 at $\%$, respectively, and 1 at $\%$ of other elements. The $\mathrm{O} / \mathrm{C}$ atomic ratios were comparable with those recently obtained by Blankenship et al. [43]. 


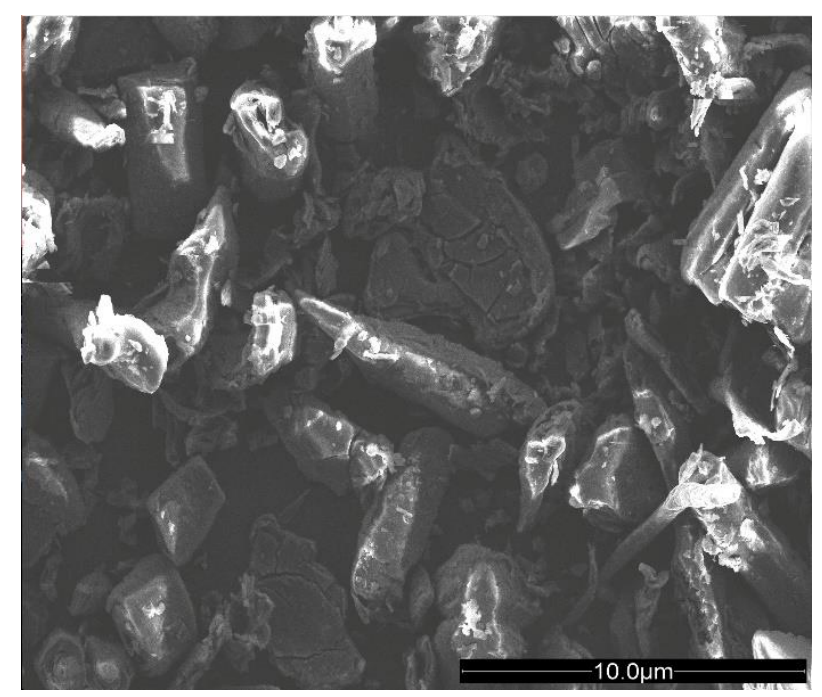

(a)

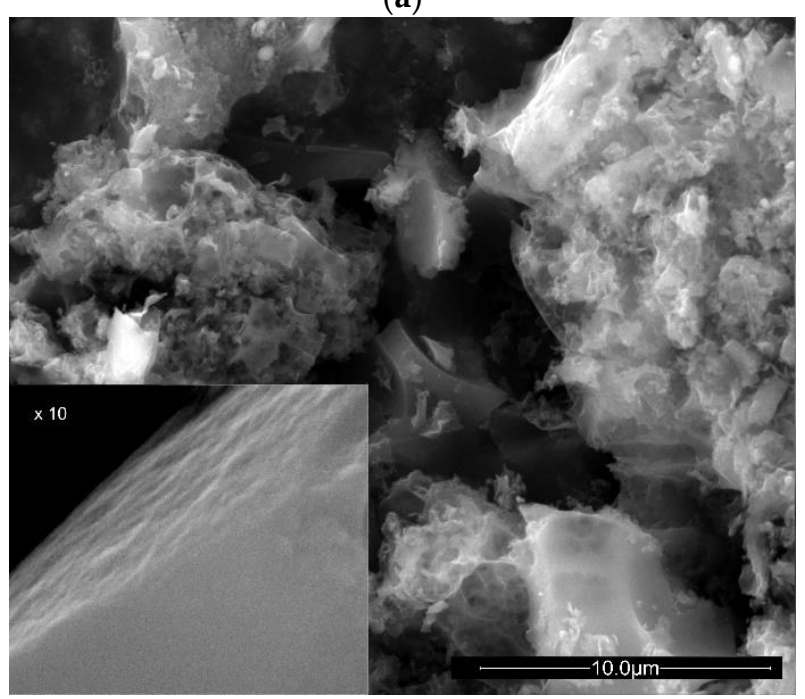

(b)

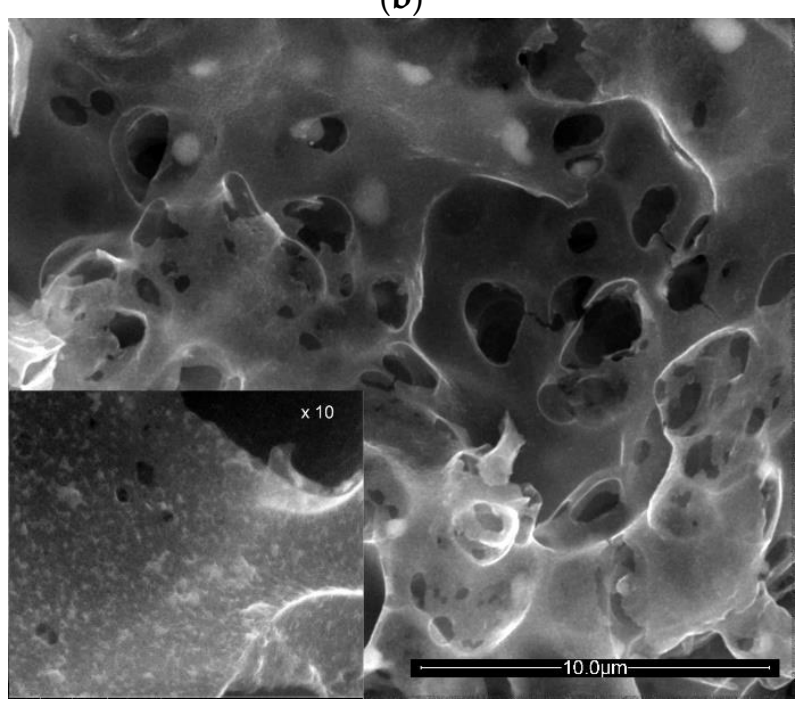

(c)

Figure 2. Cont. 


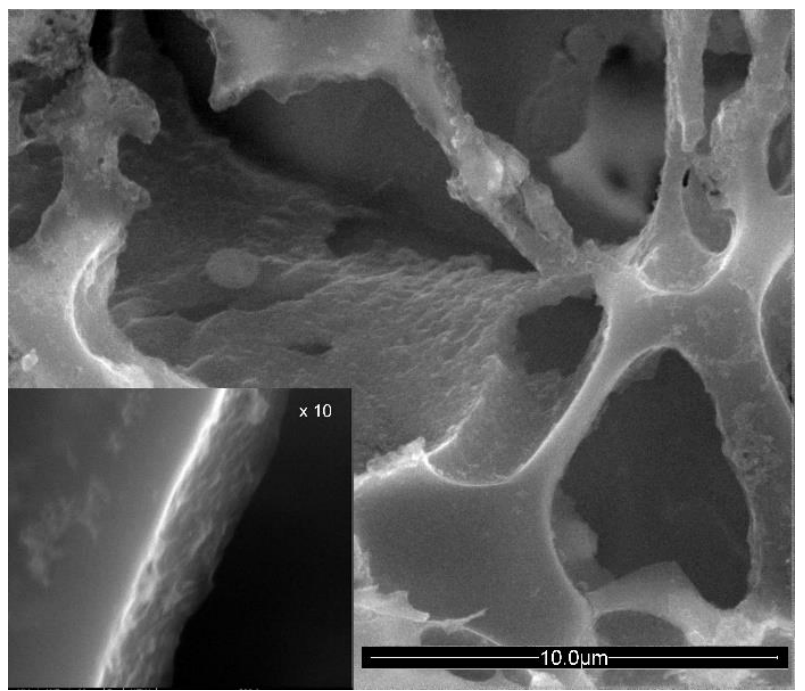

(d)

Figure 2. SEM images of (a) DPC, (b) ADPC0.5, (c) ADPC1, and (d) ADPC3. The insets in (a), (b), (c), and $(\mathrm{d})$ show further magnified images.

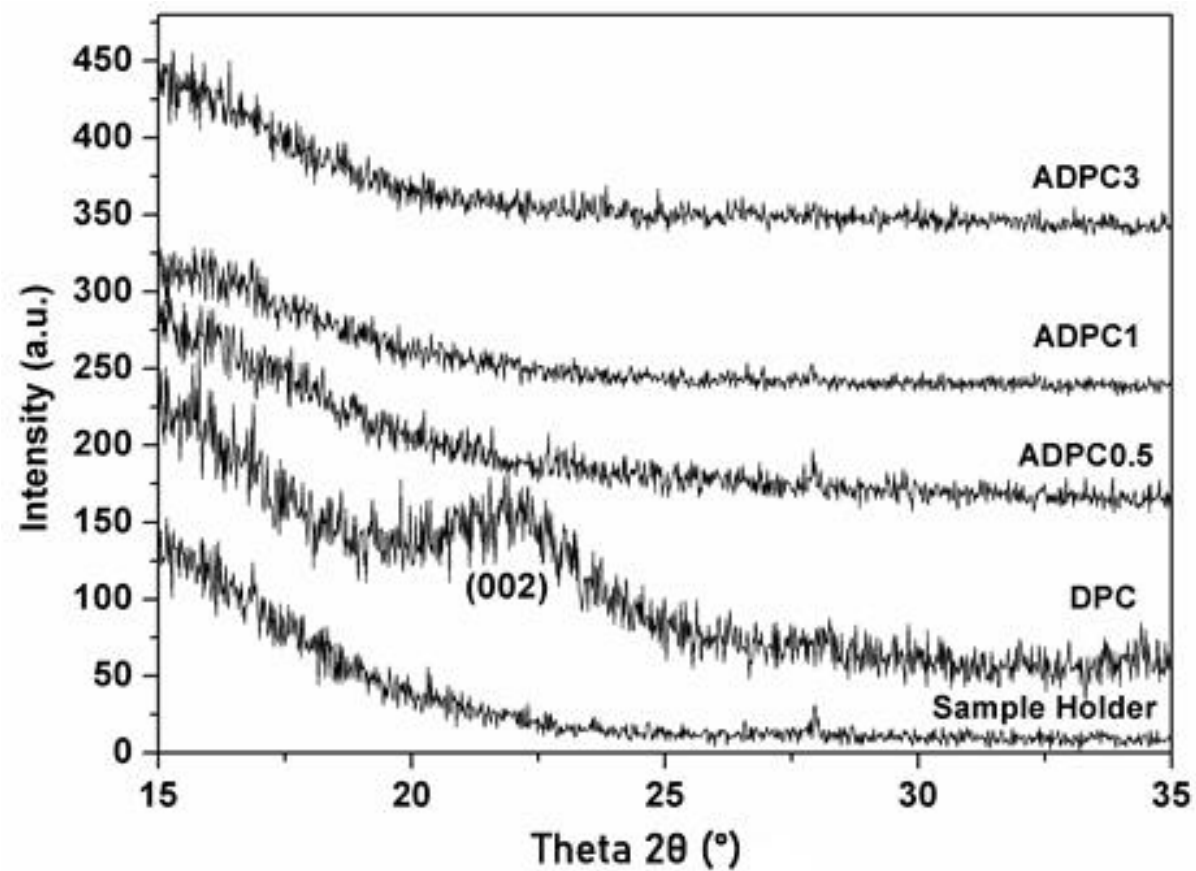

Figure 3. XRD pattern of samples between $2 \theta=15^{\circ}$ and $37^{\circ}$. The complete spectrum is shown in Figure S1.

\subsection{Textural Properties Analysis}

Figure 4 shows the nitrogen adsorption/desorption isotherms as measured at the liquid nitrogen temperature. Here, as later, for the sake of clarity, only the curves of the most significant samples are shown. As expected, the DPC sample did not show an appreciable $\mathrm{N}_{2}$ uptake (here not shown), indicating that the sample had a very low porosity and confirming the SEM analysis results. According to the IUPAC classification [48], the shapes of the isotherms were of types I and IV. This was related to a developed mesopore structure coexisting with a microporous framework. The $\mathrm{N}_{2}$ uptake rapidly increased at a very low relative pressure $\left(\mathrm{P} / \mathrm{P}_{0}<0.01\right)$ for all the measured isotherms, which is as an indication of their microporous character; an indication of their micropore 
capacity was connected to the quasi-horizontal plateau in the range $\mathrm{P} / \mathrm{P}_{0}>0.1$, and a hysteresis loop at the relative pressure range of $0.4-1.0$, which was associated with the capillary condensation that occurred in mesopores.

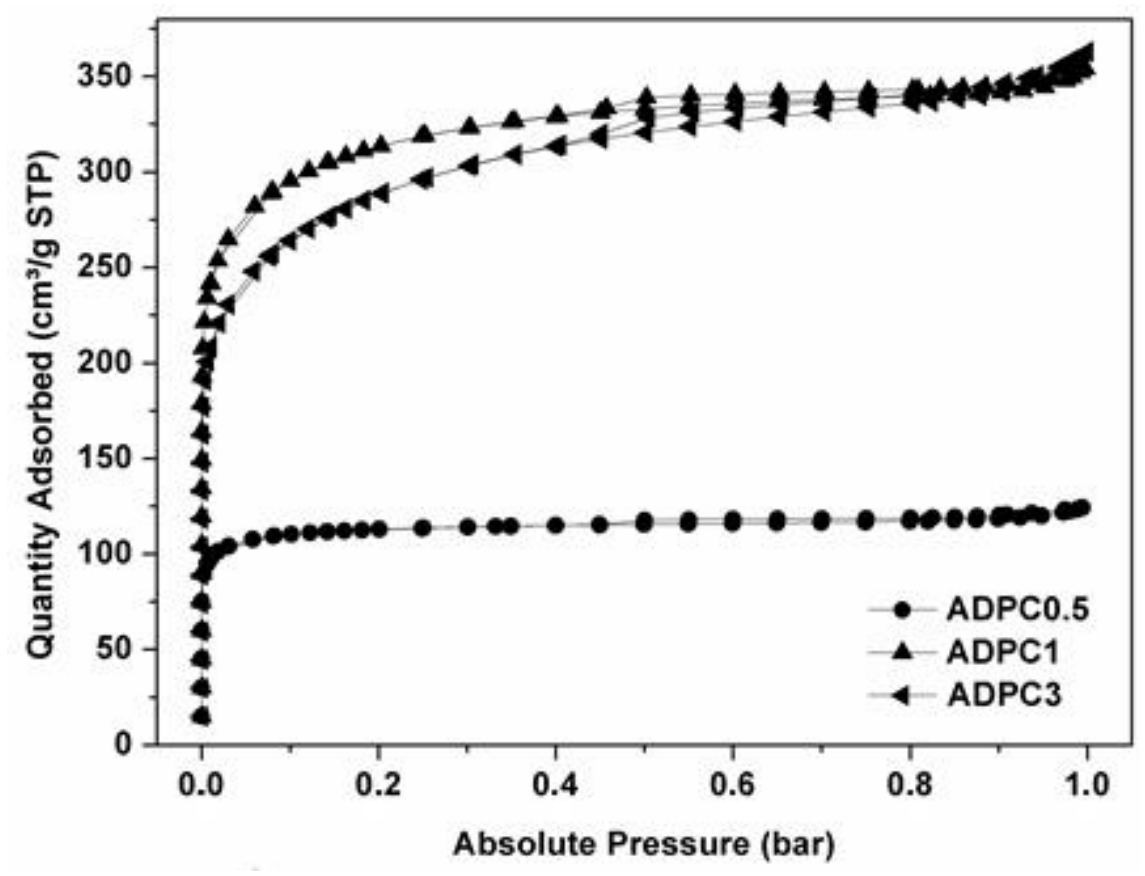

Figure 4. $\mathrm{N}_{2}$ adsorption-desorption isotherms at $77 \mathrm{~K}$.

By looking at the curves' details, it can be noted that the ADPC0.5 sample had a narrower isothermal knee and a less extensive hysteresis loop than the other samples, indicating mainly microporous structures with a lower mesoporosity. On the contrary, the other samples showed a much more considerable amount of adsorbed $\mathrm{N}_{2}$ at low pressures, which is symptomatic of a higher microporosity; furthermore, the more extensive broadening of the isotherm flection point, as well as of the hysteresis loop, was representative of both an increase of the micropore width and the development of mesoporosity, as already shown in the SEM investigation. In particular, the ADPC3 sample exhibited the greatest knee widening, which was indicative of a greater mesoporosity (Table 1). This can be linked to the micropores removal and the development of the mesopores due to the excessive $\mathrm{KOH}$ content [33-35]. The examination of the adsorption isotherms and PSDs allowed us to quantify these structural differences, as reported in Table 1.

The PSDs were evaluated using DFT and the cumulative volume, as shown in Figure 5, clearly shows that the activation process increased the size of the micropores and generated mesopores. All the PSD plots (Figure S2) exhibited a significant peak in the ultra-microporous region centered around $0.5 \mathrm{~nm}$ and series of peaks in the microporous region, whereas the pore size range extended into the mesoporous area only for the samples with a $\mathrm{KOH} / \mathrm{DPC}$ ratio higher than 0.5 . The porosity was therefore homogenous and concentrated in a narrow range $(<1 \mathrm{~nm})$, which is a crucial feature for effective $\mathrm{H}_{2}$ adsorption. All these observations point out that $\mathrm{KOH} / \mathrm{PC}$ ratio was a critical factor in the development of porosity during the activation process. More specifically, increasing the impregnation ratio increased the microporosity (Figure 6), which reached its highest value when the $\mathrm{KOH} / \mathrm{DPC}$ ratio was equal to 1 . At higher $\mathrm{KOH} / \mathrm{DPC}$ ratios, we observed the development of the mesoporosity of ACs in the 20-200 $\AA$ range, which is an essential characteristic for their application in different fields [49]. Furthermore, when comparing the cumulative volume curve for the ADPC3 and ADPC1 samples, a rigid shift was evident showing that while the latter had a dominant microporous character (pore dimensions were essentially confined below $30 \AA$ ), the former developed a mesoporous character. In fact, calculating the difference between the cumulative volume of ADPC1 and that of 
ADPC3 (Figure S3), it is noted that this tended to increase up to a maximum of around $15 \AA$ and then decreased, thus highlighting the greater microporous character of the first sample relative to the second, as well as the ability of this process to finely tune the material porosity. Furthermore, the probed pinecone AC samples presented a higher micropore fraction relative to other biomass activated carbons $[7,23,25,27,33]$.

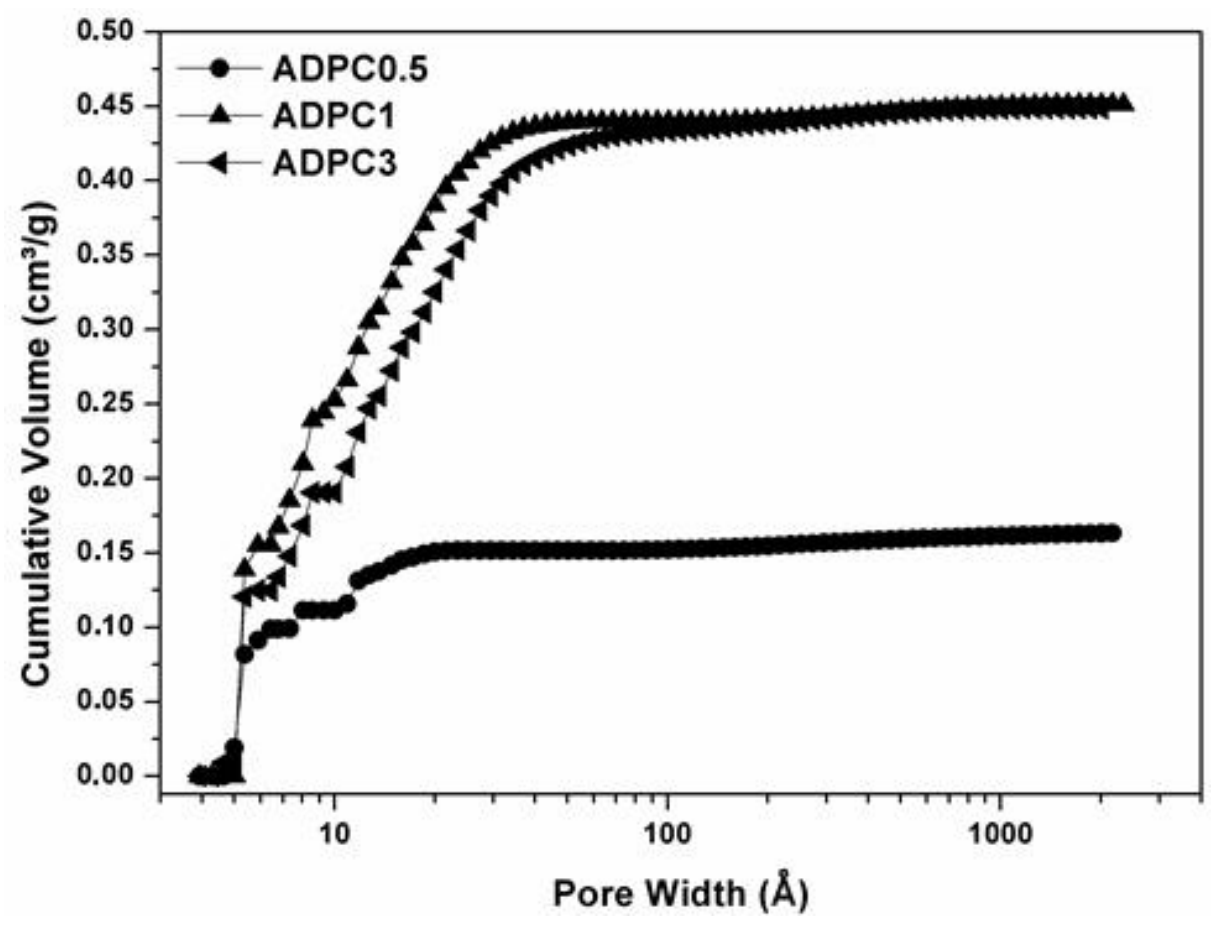

Figure 5. Cumulative pore volume of the analyzed samples.

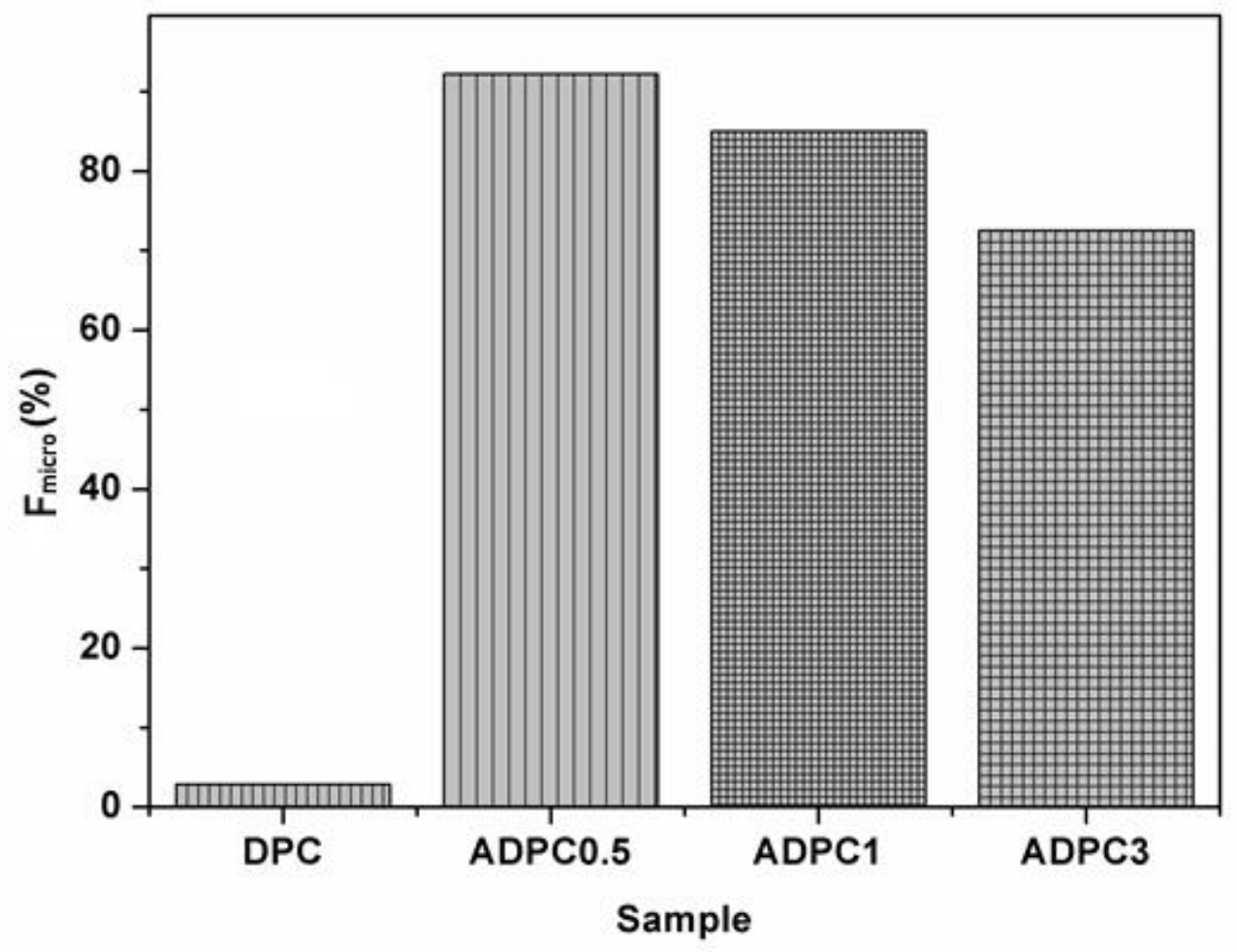

Figure 6. Micropore volume fractions (see Table 1 for the acronym definitions). 
The textural properties, as recovered via the analysis of the $\mathrm{N}_{2}$ adsorption isotherms, are summarized in Table 1, where the fractions of ultra-micropores, super-micropores, and mesopores were evaluated in accordance with the pore classification given by IUPAC [48]. As seen, the KOH/PC ratio influenced the textural properties (Figure $\mathrm{S} 4)$, in particular the microporous fraction $\left(\mathrm{F}_{\text {micro }}\right)$, which decreased as the $\mathrm{KOH} / \mathrm{PC}$ ratio increased. The increase of the $\mathrm{KOH} / \mathrm{PC}$ ratio involved damage to the structure, which reduced $\mathrm{F}_{\text {micro, }}$ and at the same time, increased the mesoporous fraction. By increasing the $\mathrm{KOH} / \mathrm{DPC}$ ratio, more $\mathrm{KOH}$ was retained into the raw material; this is an advantage because the activation reaction proceeded more effectively with more micropores being created in the raw material. On the other hand, as a drawback, the same process produced damage in the already produced porous structure.

ADPC 0.5 showed the highest microporous fraction, confirming the microporous nature of this sample, although the total micropore volume was very low. ADPC1 presented the highest micropore volume $\left(0.383 \mathrm{~cm}^{3} / \mathrm{g}\right)$ and BET surface area $\left(1173 \mathrm{~m}^{2} / \mathrm{g}\right)$. These parameters decreased when the $\mathrm{KOH} / \mathrm{DPC}$ ratio increased above 1.

Comparing the obtained results with the literature [23-25,27,28,33,43], while the PSD was similar and both the $\mathrm{V}_{\mathrm{T}}$ and SSA showed lower values, the ADPCs had both a higher oxygen content and microporous fraction, showing that the synthesis of highly microporous carbon for $\mathrm{H}_{2}$ uptake can take advantage of the use of pinecones as biomass precursors, while the optimization of the activation procedure parameters could further improve this feature.

\subsection{Hydrogen Adsorption}

To have a preliminary estimation and comparison of the $\mathrm{H}_{2}$ storage capacity of all the analyzed samples, hydrogen adsorption/desorption measurements (see Figure 7) were undertaken at liquid nitrogen temperature $(77 \mathrm{~K})$ in the $0-1$ bar range.

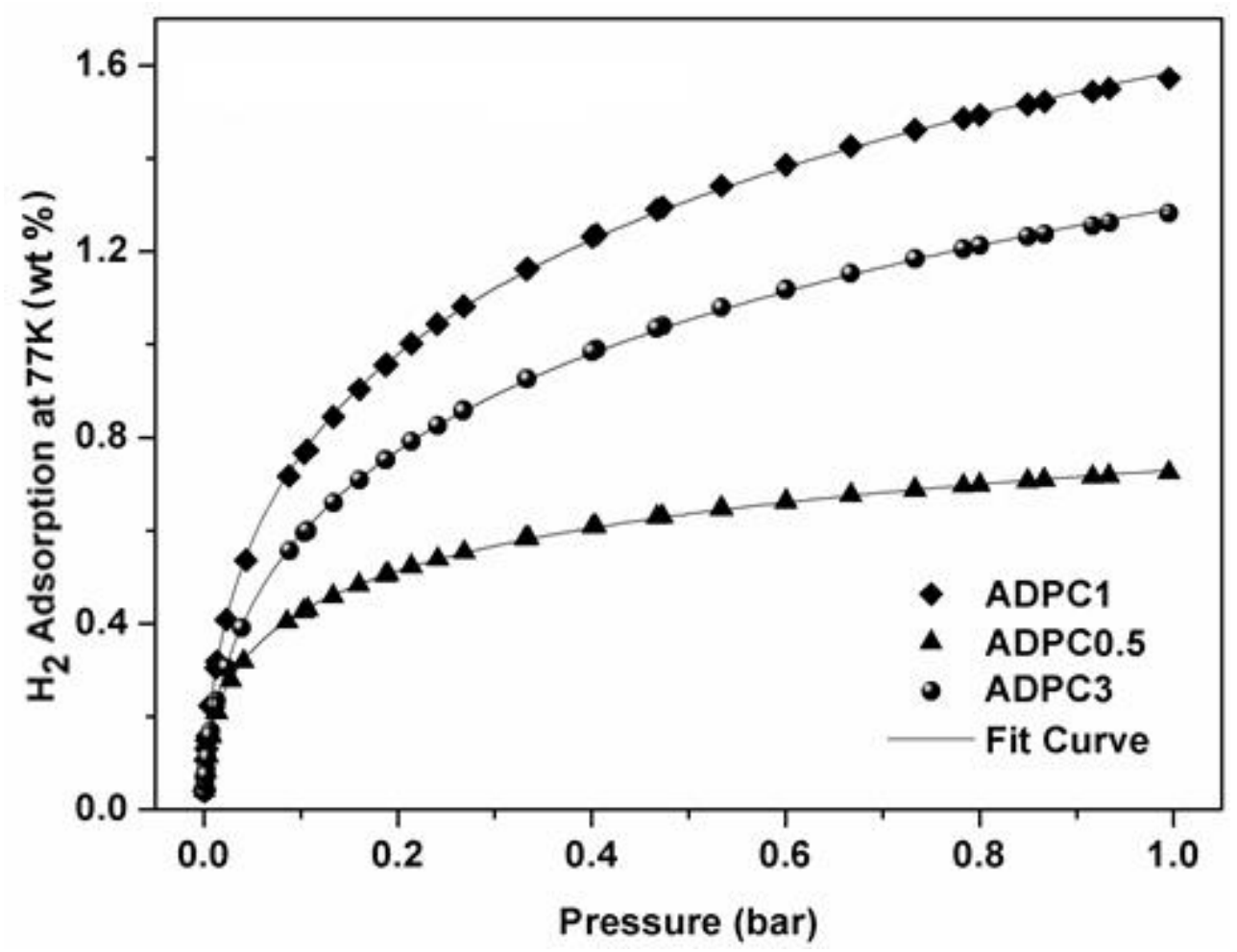

Figure 7. $\mathrm{H}_{2}$ adsorption isotherms at $77 \mathrm{~K}$ up to 1 bar.

The $\mathrm{H}_{2}$ uptake was as low as $0.38 \mathrm{wt} \%$ in the DPC sample, while higher storage capacities were observed for the activated samples. This trend was expected $[23,30,33]$, as we have reported that 
a larger SSA and micropore volume boosts the $\mathrm{H}_{2}$ absorption [35]. To illustrate this, Figure 8 , using the data of Table 1, shows the trend of absorption as a function of the micropore volume and the SSA for the different samples. It is evident from Figure 8 that the $\mathrm{H}_{2}$ uptake increased with the increase of the aforementioned textural properties. This behavior occurred because carbon materials with a high micropore volume maximize the interaction potential between the hydrogen molecules and the carbon surface due to the overlap between potential fields, leading to the pore filling and therefore higher $\mathrm{H}_{2}$ adsorption.

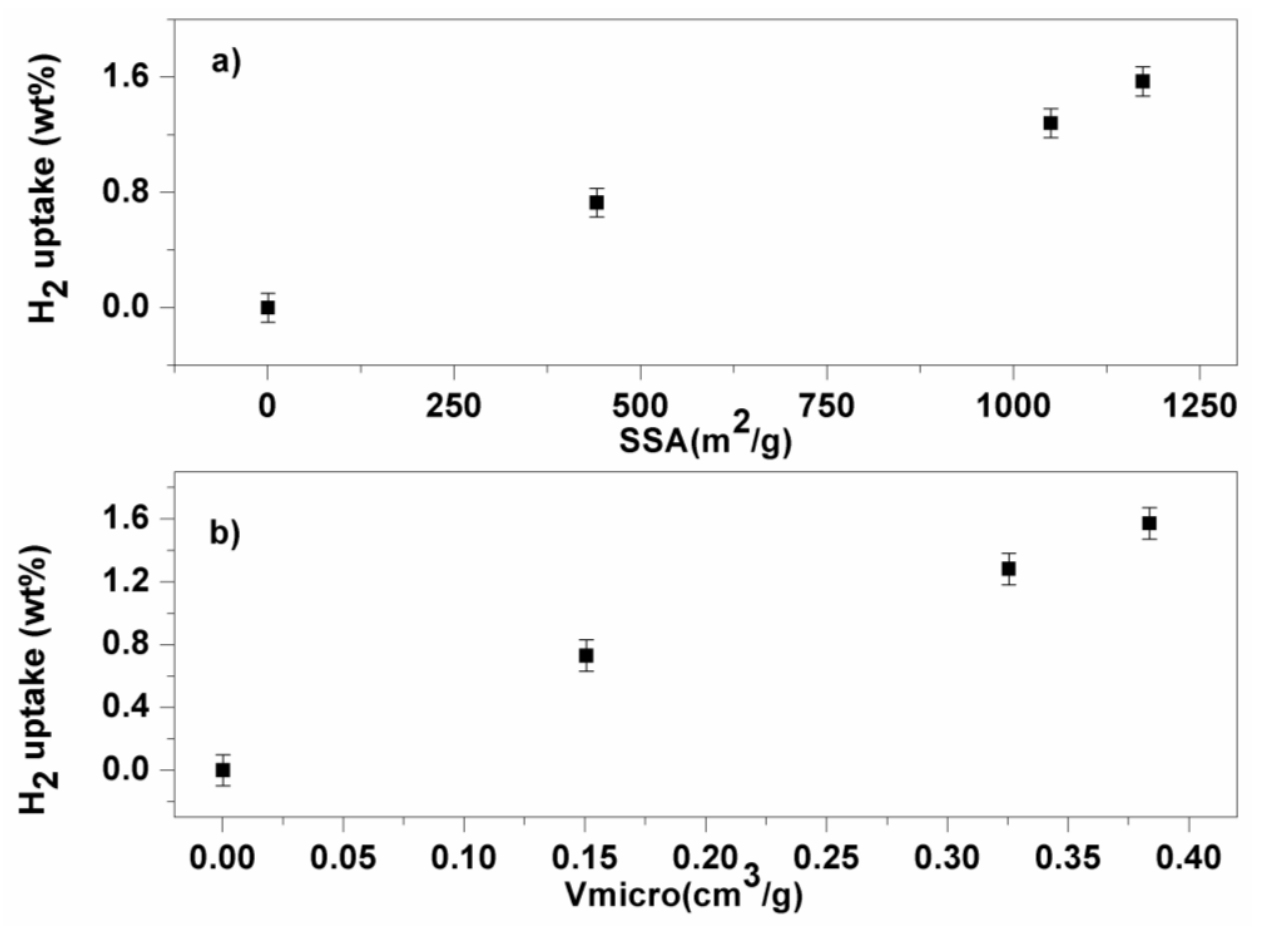

Figure 8. (a) $\mathrm{H}_{2}$ uptake at 1 bar and $77 \mathrm{~K}$ vs. SSA. (b) $\mathrm{H}_{2}$ uptake at 1 bar and $77 \mathrm{~K}$ vs. $\mathrm{V}_{\text {micro }}$.

The highest $\mathrm{H}_{2}$ uptake was obtained for the ADPC1 sample (1.6 wt\%) and it was comparable to the literature data [33], taking into account the differences in the textural parameters and their compensation effects. The ADPC3 sample showed a similar absorption capacity at 1 bar, as expected due to their textural properties. To estimate the trend of the samples' adsorption properties, the experimental data were fitted using the Töth equation [50]:

$$
w t \%=\frac{w t \% \max \left(K P_{\text {eq }}\right)}{\left(1+\left(K P_{\text {eq }}\right)^{t}\right)^{\frac{1}{t}}}
$$

where $t$ is the Töth parameter, which is a measure of the degree of homogeneity of the pore surface; $w t \%_{\max }$ is the absorption capacity of $\mathrm{H}_{2}$ that is asymptotically reached at high pressures; and $K$ is the kinetic equilibrium constant that represents the energy interaction between gas molecules and pore surfaces. The latter takes into account the affinity of the samples toward the binding of hydrogen molecules on the surface, as well as the occupancy rate of the adsorption sites. The values of these parameters are given in Table 2. 
Table 2. Töth equation fitting parameters for the activated samples.

\begin{tabular}{cccc}
\hline Sample & $\boldsymbol{w} \boldsymbol{t}_{\text {max }} \pm \boldsymbol{\Delta} \boldsymbol{w} \boldsymbol{t} \%$ & $\boldsymbol{t} \pm \boldsymbol{\Delta t}$ & $\boldsymbol{K} \pm \boldsymbol{\Delta} \boldsymbol{K}$ \\
\hline ADPC0.5 & $1.634 \pm 0.2$ & $0.254 \pm 0.005$ & $4.401 \pm 0.03$ \\
\hline ADPC1 & $5.435 \pm 0.2$ & $0.244 \pm 0.005$ & $2.858 \pm 0.03$ \\
\hline ADPC3 & $4.980 \pm 0.2$ & $0.242 \pm 0.005$ & $2.587 \pm 0.03$ \\
\hline
\end{tabular}

The $t$ parameter was similar, within the error, for all the analyzed samples, which indicated an equal and low homogeneity $(t \approx 0.25)$ of the surface adsorption sites. Notably, the $K$ values of ADPC 1 and ADPC 3 samples were very close, indicating their similar adsorption sites and adsorption mechanism (Table 2). This is also clearly visible by examining the curvature of the isotherms (Figure 7). Exceptionally, the ADPC0.5 sample showed higher $K$ values compared to the other samples, indicating a much quicker saturation at the adsorption sites.

From the analysis reported in Figure 7, it is quite evident that the adsorption isotherms of the different samples did not approach saturation, which suggests that a higher uptake was possible by increasing the pressure. Consequently, the $\mathrm{H}_{2}$ adsorption measurements were performed at liquid nitrogen temperatures $(77 \mathrm{~K})$ up to 80 bar.

The $77 \mathrm{~K}$ isotherms showed a maximum storage capacity at 80 bar (Figure 9) that moved from a minimum value of $\approx 1.8 \mathrm{wt} \%$ for the ADPC0.5 sample to a maximum value of $\approx 5.5 \mathrm{wt} \%$ for ADPC1. Cycles following the first cycle led to a slight lowering of the maximum adsorption capacity that could be quickly recovered using a mild thermal treatment at $473 \mathrm{~K}$ for $12 \mathrm{~h}$ (Figure S5). The faint trapping of the $\mathrm{H}_{2}$ molecules by the ADPCs pores suggested that a weak physisorption process was involved in the interaction between the sorbent and adsorbate, allowing for a completely reversible isotherm, which is different from ultra-microporous commercial ACs [51].

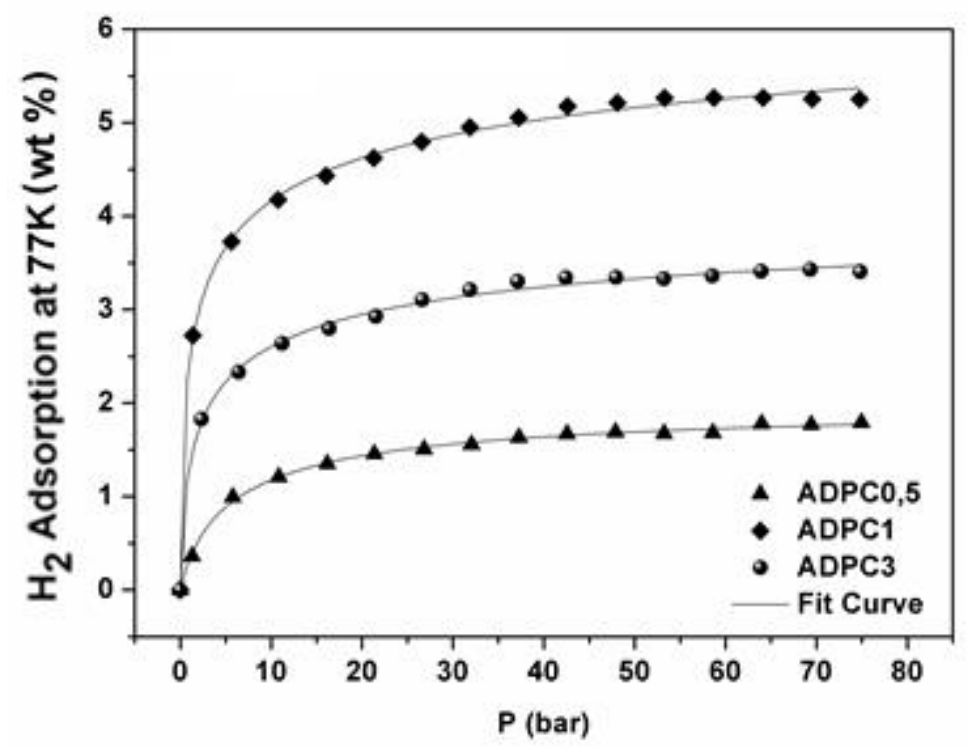

Figure 9. $\mathrm{H}_{2}$ adsorption isotherms at $77 \mathrm{~K}$ up to 80 bar. The magnitude of the error is the size of the symbol itself. Solid lines represent fits to the Töth equation.

It is important to highlight that the $\mathrm{H}_{2}$ uptake trend when moving to a higher pressure (see Figure 10) was the same as that observed at 1 bar (Figure 8), confirming the relationship between absorption and the textural properties. Our results show the non-universality of the Chahine rule $[30,36,37]$ for the ultra-microporous samples with a high oxygen content. In fact, the ADPC1 sample, whose SSA was equal to $1173 \mathrm{~m}^{2} / \mathrm{g}$, showed an asymptotic uptake (Figure 10a) close to $5.5 \mathrm{wt} \%$, i.e., $14 \mathrm{H}_{2}$ molecules $/ \mathrm{nm}^{2}$, which was more than double that of the expected value. Similar results were 
found for all the analyzed samples. Furthermore, we note that the $\mathrm{H}_{2}$ uptake was also proportional to the micropore volume (Figure 10b). Consequently, although the SSA of the analyzed sample was not very large compared to that of similar ACs [26,39], the $\mathrm{H}_{2}$ uptake of the analyzed samples attained high and remarkable values.

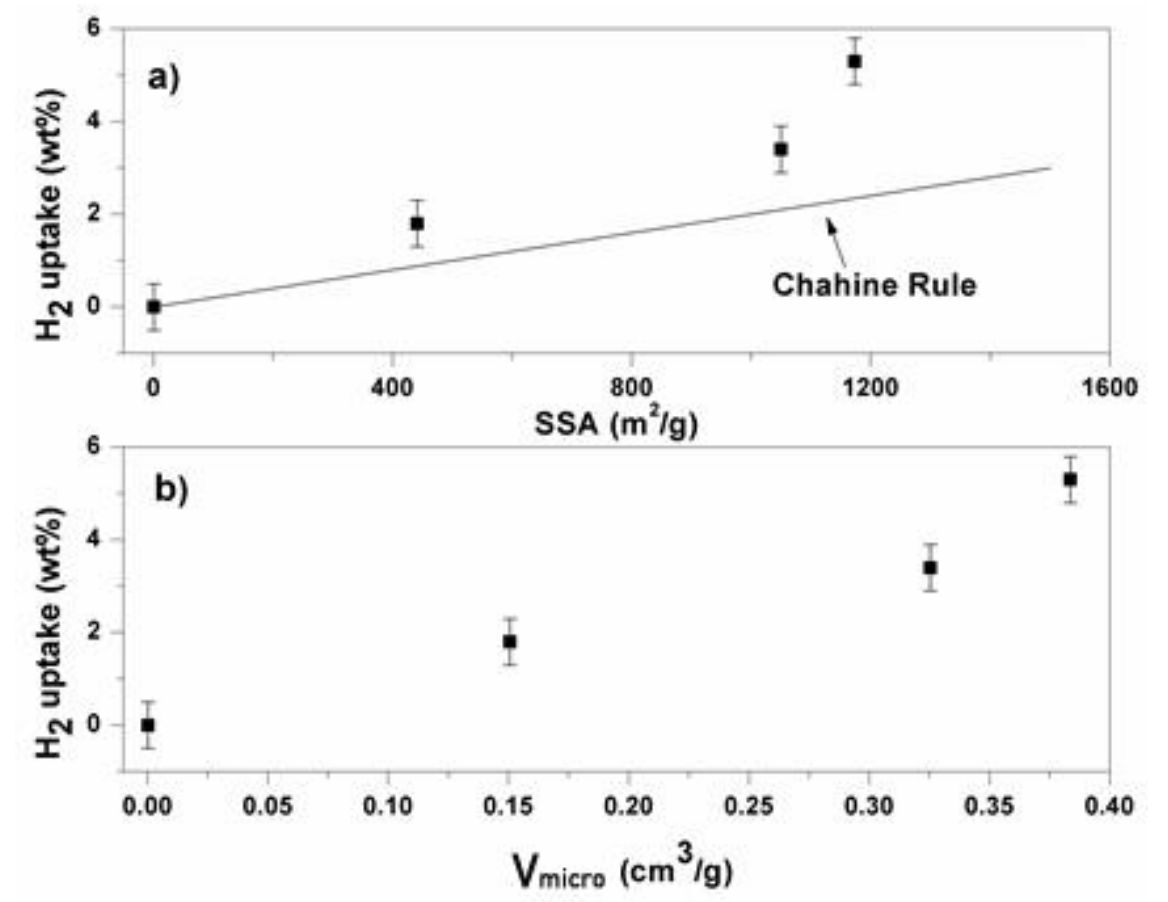

Figure 10. (a) $\mathrm{H}_{2}$ uptake at 80 bar and $77 \mathrm{~K}$ vs. SSA. (b) $\mathrm{H}_{2}$ uptake at 80 bar and $77 \mathrm{~K}$ vs. $\mathrm{V}_{\text {micro }}$.

\section{Conclusions}

Activated microporous carbon suitable for $\mathrm{H}_{2}$ storage applications were successfully prepared from stone pine (Pinus pinea) collected from the local area of Sila, Calabria, Italy, using $\mathrm{KOH}$ activation processes. All samples showed a pore size distribution centered around $0.5 \mathrm{~nm}$, a fraction micropore volume higher than $50 \%$, and an atomic $\mathrm{O} / \mathrm{C}$ ratio close to $20 \%$. The highest micropore volume, $0.383 \mathrm{~cm}^{3} \mathrm{~g}^{-1}$, was obtained when the ratio between the dehydrated pinecones biomass and $\mathrm{KOH}$ was $1: 1$. This sample showed the best $\mathrm{H}_{2}$ storage capacity values at $77 \mathrm{~K}: 1.6 \mathrm{wt} \%$ at 1 bar and $5.25 \mathrm{wt} \%$ at 80 bar. These results went well beyond the Chahine rule with an increase of more than $150 \%$ relative to the expected values. In conclusion, this work demonstrated that by using pinecone biomass as raw material, together with a small amount of $\mathrm{KOH}$ and using a simple process, it was possible to produce activated carbon with a high microporosity and a residual oxygen content. Furthermore, we showed that the activated carbon's porosity could be tuned by modifying the production parameters, allowing for tailoring it for several uses, such as adsorbed natural gas applications, gas separation through molecular sieving, and $\mathrm{CO}_{2}$ capture.

Supplementary Materials: The following are available online at http://www.mdpi.com/1996-1073/13/9/2237/s1, Figure S1: XRD pattern, Table S1: Percentual Chemical Composition of ADPC samples, Figure S2: PSD of all samples, Figure S3: Difference between ADPC1 and ADPC3 Cumulative Volume, Figure S4: Textural properties vs. $\mathrm{KOH} / \mathrm{PC}$ Ratio (a) SBET; (b) VT; (c) PSD and (d) Fraction of mesopore volume. See table 1 for acronyms, Figure S5: $\mathrm{H} 2$ uptake as function of equilibrium pressure at 77K in (a) ADPC0.5 (b) ADPC1 and (c) ADPC3.

Author Contributions: Conceptualization, S.S.; Methodology, S.S.; Validation, G.C., S.S., and A.P.; Formal Analysis, S.S., G.C., and A.P.; Investigation, G.D., A.A., G.C., and A.P.; Data Curation, G.C., S.S., and A.P.; Writing-Original Draft Preparation, S.S., A.P., and G.C.; Writing—Review \& Editing, S.S., A.P., G.C., and R.G.A.; Supervision, A.P., and R.G.A.; Project Administration, R.G.A.; Funding Acquisition, R.G.A. All authors have read and agreed to the published version of the manuscript.

Funding: This research was supported by the PON03PE_00092_1 (EOMAT). 
Acknowledgments: The authors want to deeply thank Mariano Davoli from Dipartimento di Biologia, Ecologia e Scienze della Terra - Università della Calabria (Italy) for providing the WDS analysis.

Conflicts of Interest: The authors declare that they have no known competing financial interests or personal relationships that could have appeared to influence the work reported in this paper.

\section{References}

1. Zervos, A.; Boer, C.L.; Tesniere, L. Mapping Renewable Energy Pathways towards 2020_EU Roadmap; European Renewable Energy Council: Brussels, Belgium, 2011.

2. Götz, M.; Kolb, T.; Reimert, R. Renewable Power-to-Gas: A technological and economic review. Renew. Energy 2016, 85, 1371-1390. [CrossRef]

3. Niaz, S.; Manzoor, T.; Pandith, H.A. Hydrogen storage: Materials, methods and perspectives. Renew. Sustain. Energy Rev. 2015, 50, 457-469. [CrossRef]

4. Ren, J.; Nicholas, M.; Shijun, L. Current research trends and perspectives on materials-based hydrogen storage solutions: A critical review. Int. J. Hydrogen Energy 2017, 42, 289-311. [CrossRef]

5. Burchell, T.D. Carbon Materials for Advanced Technologies; Elsevier Science Ltd.: Oxford, UK, 1999.

6. Peng, S.; Li, L.; Tian, L.L.; Adams, S. Electrospun carbon nanofibers and their hybrid composites as advanced materials for energy conversion and storage. Nano Energy 2016, 22, 361-395. [CrossRef]

7. Policicchio, A.; Maccallini, E.; Ciuchi, F.; Giordano, G. Higher methane storage at low pressure and room temperature in new easily scalable large-scale production activated carbon for static and vehicular applications. Fuel 2013, 104, 813-821. [CrossRef]

8. Pantò, F. Electrospun $\mathrm{C} / \mathrm{GeO} 2$ paper-like electrodes for flexible Li-ion batteries. Int. J. Hydrogen Energy 2017, 42, 28102-28112. [CrossRef]

9. Faye, O.; Szpunar, J.A. An Efficient Way To Suppress the Competition between Adsorption of H2 and Desorption of nH2-Nb Complex from Graphene Sheet: A Promising Approach to H2 Storage. J. Phys. Chem. C 2018, 122, 28506-28517. [CrossRef]

10. Faye, O.; Tanveer, H.; Amir, K.; Jerzy, S. Tailoring the capability of carbon nitride (C3N) nanosheets toward hydrogen storage upon light transition metal decoration. Nanotechnology 2018, 30, 075404. [CrossRef]

11. Gajdics, M.S.T.; Kovács Kis, V.; Béke, F.; Novák, Z.; Schafler, E.; Révész, Á. Microstructural Investigation of Nanocrystalline Hydrogen-Storing Mg-Titanate Nanotube Composites Processed by High-Pressure Torsion. Energy 2020, 13, 563. [CrossRef]

12. Gadipelli, S. Superior Multifunctional Activity of Nanoporous Carbons with Widely Tunable Porosity: Enhanced Storage Capacities for Carbon-Dioxide, Hydrogen, Water, and Electric Charge. Adv. Energy Mater. 2020, 10, 1903649. [CrossRef]

13. Belaustegui, Y.; Zorita, S.; AntonuccI, P.; Panto, F. Electro-spun graphene-enriched carbon fibres with high nitrogen-contents for electrochemical water desalination. Desalination 2018, 428, 40-49. [CrossRef]

14. Yang, J.; Yue, L.; Hu, X.; Zhao, Y.; Lin, Y. Efficient CO2 Capture by Porous Carbons Derived from Coconut Shell. Energy Fuels 2017, 31, 4287-4293. [CrossRef]

15. Titirici, M.-M.; White, R.J.; Brun, N. Sustainable carbon materials. Chem. Soc. Rev. 2015, 44, 250-290. [CrossRef] [PubMed]

16. Wang, J.; Ding, B.; Dong, S.Y.; Hao, X.D. Biomass derived carbon for energy storage devices. J. Mater. Chem. A 2017, 5, 2411-2428. [CrossRef]

17. Schröder, E.; Oechsler, K.T.B.; Herberger, S. Activated Carbon from Waste Biomass. In Progress in Biomass and Bioenergy Production; Shaukat, S.S., Ed.; IntechOpen, University of Karachi: Karachi, Sindh, Pakistan, 2011.

18. Khalil, H.P.S.A.; Jawaid, M. Activated Carbon from Various Agricultural Wastes by Chemical Activation with KOH: Preparation and Characterization. J. Biobased Mater. Bioenergy 2013, 7, 708-714. [CrossRef]

19. Zhang, F.; Li, G.-D.; Chen, J.-S. Effects of raw material texture and activation manner on surface area of porous carbons derived from biomass resources. J. Colloid Interface Sci. 2008, 327, 108-114. [CrossRef]

20. Deng, J.; Li, M.; Wang, Y. Biomass-derived carbon: Synthesis and applications in energy storage and conversion. Green Chem. 2016, 18, 4824-4854. [CrossRef]

21. Gao, Z. Biomass-derived renewable carbon materials for electrochemical energy storage. Mater. Res. Lett. 2017, 5, 69-88. [CrossRef] 
22. Wang, H.; Yu, W.; Shi, J.; Mao, N. Biomass derived hierarchical porous carbons as high-performance anodes for sodium-ion batteries. Electrochim. Acta 2016, 188, 103-110. [CrossRef]

23. Zhang, C.; Geng, Z.; Cai, M.; Zhang, J. Microstructure regulation of super activated carbon from biomass source corncob with enhanced hydrogen uptake. Int. J. Hydrogen Energy 2013, 38, 9243-9250. [CrossRef]

24. Xiao, Y.; Dong, H.; Long, C.; Zheng, M.T. Melaleuca bark based porous carbons for hydrogen storage. Int. J. Hydrogen Energy 2014, 39, 11661-11667. [CrossRef]

25. Heo, Y.-J.; Park, S.-J. Synthesis of activated carbon derived from rice husks for improving hydrogen storage capacity. J. Ind. Eng. Chem. 2015, 31, 330-334. [CrossRef]

26. Bader, N.; Ouederni, A. Optimization of biomass-based carbon materials for hydrogen storage. J. Energy Storage 2016, 5, 77-84. [CrossRef]

27. Choi, Y.-K.; Park, S.-J. Preparation and characterization of sucrose-based microporous carbons for increasing hydrogen storage. J. Ind. Eng. Chem. 2015, 28, 32-36. [CrossRef]

28. Ramesh, T.; Rajalakshmi, N.; Dhathathreyan, K.S. Synthesis and characterization of activated carbon from jute fibers for hydrogen storage. Renew. Energy Environ. Sustain. 2017, 2, 4. [CrossRef]

29. Manocha, S. Activated carbon from biomass. AIP Conf. Proc. 2013, 1538, 120-123.

30. Jiménez, V.; Paula, S. Hydrogen storage in different carbon materials: Influence of the porosity development by chemical activation. Appl. Surf. Sci. 2012, 258, 2498-2509. [CrossRef]

31. Min, S.; Bao, S.; Jin, R.; Xiao, L.; Wu, Y.; Zhong, Z.; Huang, Y.J. The comparison of two activation techniques to prepare activated carbon from corn cob. Biomass Bioenergy 2013, 48, 250-256.

32. Härmas, M. Microporous-mesoporous carbons for energy storage synthesized by activation of carbonaceous material by zinc chloride, potassium hydroxide or mixture of them. J. Power Sources 2016, 326, 624-634. [CrossRef]

33. Sethia, G.; Sayari, A. Activated carbon with optimum pore size distribution for hydrogen storage. Carbon 2016, 99, 289-294. [CrossRef]

34. Wang, J.; Kaskel, S. KOH activation of carbon-based materials for energy storage. J. Mater. Chem. 2012, 22, 23710-23725. [CrossRef]

35. Minoda, A. Synthesis of $\mathrm{KOH}$-activated porous carbon materials and study of hydrogen adsorption. J. Alloy. Compd. 2013, 580, S301-S304. [CrossRef]

36. Masika, E.; Mokaya, R. Hydrogen Storage in High Surface Area Carbons with Identical Surface Areas but Different Pore Sizes: Direct Demonstration of the Effects of Pore Size. J. Phys. Chem. C 2012, 116, 25734-25740. [CrossRef]

37. Gogotsi, Y. Importance of pore size in high-pressure hydrogen storage by porous carbons. Int. J. Hydrogen Energy 2009, 34, 6314-6319. [CrossRef]

38. Cabria, I.; López, M.J.; Alonso, J.A. The optimum average nanopore size for hydrogen storage in carbon nanoporous materials. Carbon 2007, 45, 2649-2658. [CrossRef]

39. Sangchoom, W.; Mokaya, R. Valorization of Lignin Waste: Carbons from Hydrothermal Carbonization of Renewable Lignin as Superior Sorbents for CO2 and Hydrogen Storage. ACS Sustain. Chem. Eng. 2015, 3, 1658-1667. [CrossRef]

40. Yang, H.; Yan, R.; Chen, H. Characteristics of hemicellulose, cellulose and lignin pyrolysis. Fuel 2007, 86, 1781-1788. [CrossRef]

41. Bello, A. Renewable pine cone biomass derived carbon materials for supercapacitor application. RSC Adv. 2016, 6, 1800-1809. [CrossRef]

42. Duman, G. Production of Activated Carbon from Pine Cone and Evaluation of Its Physical, Chemical, and Adsorption Properties. Energy Fuels 2009, 23, 2197-2204. [CrossRef]

43. Blankenship Ii, T.S.; Balahmar, N.; Mokaya, R. Oxygen-rich microporous carbons with exceptional hydrogen storage capacity. Nat. Commun. 2017, 8, 1545. [CrossRef]

44. Brunauer, S.; Emmett, P.H.; Teller, E. Adsorption of Gases in Multimolecular Layers. J. Am. Chem. Soc. 1938, 60, 309-319. [CrossRef]

45. Seaton, N.A.; Walton, J.P.R.B.; Quirke, N. A new analysis method for the determination of the pore size distribution of porous carbons from nitrogen adsorption measurements. Carbon 1989, 27, 853-861. [CrossRef]

46. Policicchio, A. Volumetric apparatus for hydrogen adsorption and diffusion measurements: Sources of systematic error and impact of their experimental resolutions. Rev. Sci. Instrum. 2013, 84, 103907. [CrossRef] [PubMed] 
47. Qu, D. Investigation of Hydrogen Physisorption Active Sites on the Surface of Porous Carbonaceous Materials. Chem. Eur. J. 2008, 14, 1040-1046. [CrossRef]

48. Sing, K.S.W.; Haul, D.H.E.L.; Pierotti, R.A.; Rouquerol, J.; Siemieniewska, T. Reporting Physisorption Data for Gas/Solid Systems. In Handbook of Heterogeneous Catalysis; Wiley-VCH Verlag GmbH \& Co. KGaA: Weinheim, Germania, 2008; pp. 1217-1230.

49. Xin, W.; Song, Y. Mesoporous carbons: Recent advances in synthesis and typical applications. RSC Adv. 2015, 5, 83239-83285. [CrossRef]

50. Toth, J. Adsorption Theory, Modeling and Analysis; Marcel Dekker: New York, NY, USA, 2020.

51. Minuto, F.D.; Aloise, A.; Policicchio, A. Liquid-like hydrogen in the micropores of commercial activated carbons. Int. J. Hydrogen Energy 2015, 40, 14562-14572. [CrossRef]

(C) 2020 by the authors. Licensee MDPI, Basel, Switzerland. This article is an open access article distributed under the terms and conditions of the Creative Commons Attribution (CC BY) license (http://creativecommons.org/licenses/by/4.0/). 